\title{
Hospitalidad y soberanía. Reflexiones políticas en torno de la filosofía de Jacques Derrida
}

\author{
Hospitality and sovereignty. Political reflections \\ on Jacques Derrida's philosophy
}

\author{
Ana Paula Penchaszadeh
}

Universidad de Buenos Aires

\begin{abstract}
RESUMEN. El presente trabajo interroga los vínculos entre soberanía y hospitalidad y la importancia deconstructiva de la segunda sobre la primera. Si bien, a primera vista, pareciera que lo que hace posible la hospitalidad como derecho efectivo es la soberanía, siguiendo los trazos de la filosofía de Jacques Derrida, se hace manifiesto que la hospitalidad, al depender de la soberanía, del derecho que se arrogan los Estados de hacer efectivo el derecho, se ve constantemente aplazada y pervertida. Existe un lazo productivo entre hostilidad y soberanía, exaltado por la teoría política clásica, que debe ser «desnaturalizado» en nombre de la hospitalidad, es decir, en nombre de una justicia infinita hacia el otro como radicalmente otro.
\end{abstract}

Palabras clave: Derrida, hospitalidad, soberanía, heteronomía, democracia, autoinmunidad.
ABstract. This work examines the links between sovereignty and hospitality and the deconstructive importance of the latter over the former. At first, it would seem that what makes hospitality possible as an effective right is sovereignty; however, following the traces of Jacques Derrida's philosophy, it is evident that hospitality, since it depends on sovereignty and on the right assumed by the States to make it effective, is constantly postponed and perverted. There is a productive link between hospitality and sovereignty, exalted by the classical political theory, which should be «denaturalized» on behalf of hospitality, that is to say, on behalf of an infinite justice towards the other as radically other.

Key words: Derrida, hospitality, sovereignty, heteronomy, democracy, autoimmunity

«Desde el siglo XVI hasta el siglo Xx, existe una continuidad entre guerra y política, la primera siendo el medio constitutivo de la segunda, su condición, continuidad característica de la modernidad política en el sentido de que la ligazón guerra/política está al servicio de una problemática del ser común pensado según el uno, es decir según el soberano. La modernidad política revela así su esencia eminentemente profana: la justicia política procede no de una forma o de una idea a priori, que viene a constituir la política desde el exterior, por fuera de ella misma, sino de una física de fuerzas. El uno, como forma múltiple, procede de la acción histórica de los hombres, guerras fundadoras y revoluciones constitutivas de un orden describiéndose a sí mismo como estado de justicia.»

(Mairet, 1997, 196. Traducido del francés por la autora) 
La soberanía constituye el principal límite a la hospitalidad. Esta curiosa sentencia encarna el dilema del orden político moderno. Sólo puede haber derecho (en el sentido amplio y restringido del término) en el marco de Estados Nacionales cuya particularidad cristaliza y efectiviza la universalidad de la ley y el devenir sujetos (de derecho) de los individuos; es decir, la hospitalidad sólo es posible como derecho en el marco de ciertas regulaciones e instituciones que cada Estado unilateralmente, en tanto cuerpo político diferenciado y autónomo, establece para la entrada y salida de las personas en su territorio. Pareciera, pues, a primera vista, que lo que hace posible la hospitalidad como derecho efectivo es la soberanía. Sin embargo, como pone en evidencia Derrida, la hospitalidad, al depender de la soberanía, del derecho que se arrogan los Estados de hacer efectivo el derecho, se ve constantemente aplazada y pervertida.

Existe un vínculo productivo entre hostilidad y soberanía que hace, al menos difícil, un postulado cosmopolita real. La comunidad se gesta y se preserva a sí misma difiriendo su violencia constitutiva hacia el extranjero. Éste, su diferencia, cruza oblicuamente cualquier intento de comprensión de las determinaciones de nuestra vida-con-otros. Constituye por sí mismo uno de los dispositivos político-existenciales más eficaces para la construcción de la identidad vía la diferencia; su negación y oposición permite la construcción de un adentro, de una identidad, desde el afuera que él evoca y representa. Los extranjeros, pues, corren serios peligros en un mundo cuyo fundamento político es la afirmación de soberanías parciales.

Hay al menos dos grandes formas interrelacionadas de concebir la soberanía, una fuertemente vinculada con la tradición teórico-política de la modernidad, que limita el problema al vínculo estado-nación-soberanía, planteando la exis- tencia de soberanías internas a los territorios nacionales y la inexistencia de una soberanía internacional; y otra, mucho más amplia, ético-filosófica que, en estrecho diálogo con la anterior, difiere la pregunta hacia el problema más amplio del sujeto y la autonomía. La primera forma de concebir la soberanía reduce el problema a una cuestión ontológico-política, mientras que la segunda abre el concepto hacia el problema ético de la ipseidad y la identidad. La teoría de Jacques Derrida se encontraría en una línea de cruce de ambas perspectivas ${ }^{1}$.

Otra línea de quiebre central en lo que hace a la definición del concepto de soberanía se refiere a su vínculo ya sea con la hostilidad o la hospitalidad. Mientras un grupo importante de autores sienta las bases para la comprensión de la soberanía en el horizonte de la hostilidad, siendo el fundamento de la identidad/ipseidad el rechazo primero del otro (se podría decir que la historia del concepto de soberanía en la teoría política moderna resume muy bien el fracaso del concepto de hospitalidad: no se puede ser un teórico de la soberanía y, al mismo tiempo, ser un teórico de la hospitalidad); otro grupo minoritario de autores plantea todo lo contrario: la hospitalidad es el acto primero, la presencia del otro antes de toda constitución del yo, que interpela a la soberanía (la constitución de un sujeto autónomo) en tanto fuente primera de indeterminación e indiferencia ${ }^{2}$. Esta segunda línea, que Derrida hace suya, no sólo tiene en cuenta las condiciones y limitaciones de la hospitalidad donde quiera que ésta existe, sino que avanza sobre una línea hiper-crítica del concepto de soberanía en nombre de la hospitalidad.

Se debe repolitizar la cuestión de la hospitalidad poniendo en cuestión no sólo la equivalencia del Estado con el Estado de Derecho ${ }^{3}$, sino también la equivalencia de política y Estado ${ }^{4}$. Nin- 
gún ordenamiento político es «exhaustivo». El sistema de pertenencia en base al anclaje del derecho en los Estados Nacionales se funda en una «lógica de simetrías», que no se condice con la realidad: no todo extranjero es ciudadano en otro lugar. La hospitalidad debe interrogar la lógica del Uno, la soberanía. Para ello se siguen aquí los trazos del pensamiento derrideano sobre la hospitalidad.

\section{I}

El concepto de soberanía es claramente un concepto moderno. Antes de que Bodino escribiera su doctrina de la soberanía en los Seis Libros de la República (1576) su uso es un anacronismo. Si bien el término soberanía (majestas) puede ser asociado a otros términos cuyos orígenes pueden remontarse a los griegos (basileus), al imperio romano (imperium) y a la Edad Media (potestas), es Bodino quien «inventa» el concepto de soberanía al exponer las principales características de los nacientes Estados europeos. Casi todas las definiciones de la soberanía que se pueden leer en enciclopedias y diccionarios repiten la frase «el Estado soberano es una tautología», pues Estado y soberanía habrían entrado en vigor prácticamente al mismo tiempo como "símbolos seculares para la fundamentación no religiosa de la autoridad» (Crick, 1979: 768). Sólo se puede comprender la unidad política moderna, el Estado Nacional, a partir del principio profano que hace posible la unión de las partes a un todo: la soberanía.

Si la existencia de un Estado soberano es la condición de existencia del orden político moderno, esto implica que el concepto de soberanía mezcla elementos descriptivos — sólo se puede entender la emergencia del concepto en el contexto de la búsqueda de un fundamento secular del Estado - con elementos prescriptivos - como sostienen Maquiavelo y Hobbes, aquellos Estados que carecen de soberanía no podrán defenderse ni de ataques externos ni de conflictos internos- (Crick, 1979: 768). La soberanía es el elemento superlativo que en todo Estado tiene el poder de crear la ley y asegurar la defensa del cuerpo político en su conjunto; es, desde sus orígenes, una figura compleja y paradójica, pues es al mismo tiempo condición y garantía de la ley ${ }^{5}$. Frente a la inexistencia de una justificación trascendente del orden político, la soberanía no sólo constituye la respuesta a la pregunta por el origen legítimo de las leyes y la sociedad política moderna, sino también la instancia que emerge cuando la estructura social, política y jurídica se ve amenazada. El concepto de soberanía tiene pues ciertas características autorreferenciales que hacen difícil su aprehensión, siendo que es la facultad del poder de autojustificarse y legitimarse por sí mismo.

A la pregunta ¿qué es la soberanía? la teoría política ha dado al menos dos respuestas. Por un lado, están aquellos que sostienen que la soberanía es la instancia decisoria por excelencia tanto en lo que se refiere a lo particular como a lo general, estableciendo una relación de implicación entre poder y soberanía (Maquiavelo, Hobbes, Schmitt). Por otro lado, están aquellos que sostienen que la soberanía es una instancia constituyente fundamental que se expide sólo sobre cuestiones que afectan de manera general al conjunto del cuerpo político y no sobre cuestiones particulares (Rousseau). Mientras la primera definición sirve para justificar formas concentradas de poder (la monarquía y la dictadura), la segunda constituye el fundamento del parlamentarismo, el constitucionalismo y el republicanismo (tanto liberal como democrático). Cabe, sin embargo, remarcar que, aún cuando se entienda por soberanía la superioridad de una instancia jurídica suprema que se encuentra por encima de las voluntades particulares y de los gobiernos (defi- 
nida por el normativismo liberal como Estado de Derecho), la mayoría de los sistemas jurídicos contienen mecanismos por los cuales, en los llamados casos de excepción, es posible suspender el conjunto de garantías y derechos normalmente reconocidos. La soberanía, por lo tanto, puede ser concebida como una instancia legal suprema, que permite regular y organizar al interior de un Estado los vínculos entre los distintos sujetos y representarlos en el exterior, $\mathrm{y}$, al mismo tiempo, como una instancia decisoria y excepcional con la capacidad de suspender legalmente el orden legal mismo para preservar la unidad del cuerpo político.

La mayoría de las Constituciones definen la soberanía de forma radical o «efectiva» a partir de la facultad de distinguir lo «normal» de lo excepcional y como la capacidad de preservar el cuerpo político de ataques internos o externos ${ }^{6}$. El gran problema que encierra entonces este concepto es que su fin es defensivo: proteger a los de adentro de los de afuera (ya sea mediante un conjunto de normas preexistentes legítimas o mediante un poder excepcional decisorio). La soberanía se hace manifiesta en tanto poder «efectivo» frente a amenazas y ataques internos y externos. La unión hacia el interior, en ausencia de una justificación a priori del orden político, se produce simultáneamente con el cierre hacia el exterior; 0 , en otras palabras, la política «real» de los Estados Nacionales sólo puede desplegarse a partir del trazado de una frontera y ésta es justamente la labor performativa de la soberanía: «crear» una unidad interna a partir de la hostilidad hacia el otro. De ahí el fuerte vínculo que existe entre soberanía y violencia, entre la posibilidad de la comunidad y la necesidad del sacrificio del otro ${ }^{7}$.

\section{II}

Una tarea ineludible para avanzar en la comprensión de concepto derrideano de hospitalidad es la revisión de su legado kantiano. Tanto el concepto de justicia como el de hospitalidad se encuentran en continuidad con el concepto de dignidad. La singularidad humana pensada desde la incalculabilidad propia de un ser que es fin en sí mismo, es una idea que Derrida toma del Kant. Sin embargo, mientras que en el segundo la justicia cristaliza teleológicamente en el derecho - no encontrando una contradicción a priori entre el derecho político, el derecho de gentes y el derecho cosmopolita (Kant, 2004, 49) - Derrida se pregunta, por el contrario, por el espacio que se crea entre un derecho, calculable y definible, y una justicia, incalculable e indefinible en consonancia con la dignidad de lo humano y la ausencia de un fin último ${ }^{8}$ : «¿Cómo articular esta justa incalculabilidad de la dignidad con el indispensable cálculo del derecho?» (Derrida, 2005, 57).

Para Derrida si bien no puede haber justicia sin derecho y viceversa, el derecho, al ser siempre condicional, nunca es totalmente justo; la justicia debe permanecer siempre incondicional e incalculable para hacer justicia a una humanidad incalculable en el hombre: «El derecho no es la justicia. El derecho es el elemento del cálculo y es justo que haya derecho: la justicia es incalculable, exige que se calcule con lo incalculable; y las experiencias aporéticas son experiencias tan improbables como necesarias de la justicia, es decir, momentos en que la decisión entre lo justo y lo injusto no está jamás asegurada por una regla» (Derrida, 1997a, 39). Aún cuando Derrida hereda una parte sustancial del cosmopolitismo kantiano, también se separa de éste para pensar una hospitalidad sin condiciones. Según éste, Kant concibe la hospitalidad como un derecho condicionado y regulado por la preexistencia de Estados soberanos, que se orienta más a la defensa del derecho a recibir que al derecho a ser re- 
cibido: la paz perpetua se ve eclipsada por la justificación de un derecho inalienable de los pueblos conformados en Estados-nación. Derrida, por el contrario, se pregunta por un derecho de hospitalidad progresivo y perfectible en la línea de una «Ley de hospitalidad incondicional ofrecida a priori a todo otro, a todo recién llegado, a cualquiera que sea» (Derrida, 1997, 57).

Para Kant la hospitalidad depende directamente de una definición del sujeto autónomo — de una cadena histórica asida por un fin último como proyecto mayor en el que el individuo mortal se desdibuja en una especie inmortal-. Para Derrida la hospitalidad sólo puede ser pensada ahí donde la dignidad del hombre se inscribe en una profunda heteronomía, habitada por mil otros siempre-ya acechando (muriendo) y destruyendo sus seguridades; ahí donde la hospitalidad, como justicia hacia el radicalmente otro (con el cual es imposible un comercio e incluso un diálogo), es acontecimiento incalculable, no programable o anticipable en función de un fin dado de antemano. Según Derrida es preciso repensar la hospitalidad en la línea de Lévinas ${ }^{9}$ que, a diferencia de Kant, habría logrado romper con el «realismo político» (que condiciona, cada vez, la justicia al derecho).

«Mientras que en Kant la institución de una paz eterna, de un derecho cosmopolítico y de una hospitalidad universal conserva la huella de una hostilidad natural, actual o amenazante, efectiva o virtual, para Lévinas sería lo contrario: la guerra misma conserva la huella testimonial de una acogida pacífica del rostro» (Derrida, 1998, 115).

Otro elemento para entender las diferencias en la concepción de la hospitalidad en Kant y en Derrida es que mientras el primero defiende un reformismo antidemocrático ${ }^{10}$ fundado en el temor a la anarquía, el segundo defiende una democracia radical fundada en el principio re- volucionario de la hospitalidad. El primero sigue tratando lo racional como un cálculo posible; el segundo traslada la cuestión de lo racional hacia lo razonable como punto de encuentro entre lo posible y lo imposible, «espera sin espera» del acontecimiento del otro cuya llegada no puede ser prevista que desborda cualquier idealismo teleológico a partir del concepto de mesianicidad.

Las distintas críticas de Derrida al derecho, y a la soberanía que lo funda, invitan a una reflexión más allá de una «economía» de la reciprocidad y del reconocimiento, cuyo primer eje se puede encontrar en la definición derrideana del don como don infinito. Se trata de un ejercicio hipercrítico del sujeto soberano y autónomo desde el cual se lee normalmente la política «real», que se pregunta por la relación del derecho (construido sobre la idea de cálculo del sujeto) con la justicia (como espacio abierto por la irrupción del radicalmente otro en su singularidad absoluta) como acontecimiento inscrito en una hospitalidad incondicional (amenazando y acechando, cada vez, al sujeto individual y estatal).

Derrida no sólo quiere poner al descubierto cómo funcionan efectivamente los Estados y cuáles son sus resortes, sino también mostrar cómo la incondicionalidad que los funda es la misma que hace posible su desnaturalización y perfeccionamiento. Es preciso pensar la hospitalidad no sólo como un derecho, desde un cálculo posible, una morada y un espacio soberano, sino también como un principio de justicia incondicional e irrestricto, para lo cual es preciso deconstruir la soberanía a partir del concepto de hospitalidad (la matriz sacrificial del otro a partir de una justicia infinita hacia el otro) y poner en cuestión el sujeto y la apropiación que éste hace de una identidad.

«Se trata siempre de responder de una morada, de su identidad, de su espacio, de sus 
límites, del ethos en cuanto estancia, habitación, casa, hogar, familia, lugar-propio. Ahora bien, deberíamos examinar ahora las situaciones en que no sólo la hospitalidad es coextensiva a la ética misma sino donde puede parecer que algunos, como ha podido decirse, ubican la ley de la hospitalidad por encima de una "moral" o de una cierta "ética"» (Derrida, 2000, 149).

Cuando Derrida sostiene que la soberanía - el carácter condicional del derecho - debe ser interpelada por la justicia - desde una radical heteronomía-, no se propone realizar una crítica de la soberanía a partir de algo externo a ella, sino de algo que es interno a su fundamento: la incondicionalidad ${ }^{11}$. Se trata de marcar desde su origen la imposibilidad de separar un adentro y un afuera, la intransigencia de una singularidad atravesada por el otro como verdadero fundamento de la posibilidad/imposibilidad de la individualidad (tanto del sujeto como del Estado). De ahí que la hospitalidad, el otro como acontecimiento que irrumpe en la propia casa exigiendo hospitalidad, no sólo se caracterice por poner en cuestión los fundamentos de la soberanía (y, en términos más generales, de la ipsei$d a d)$, sino también por hacer visible la arbitrariedad de lo común y lo propio, la porosidad de sus fronteras. La presencia del extranjero coloca a aquellos que deben recibirlo o expulsarlo en el camino de la duda, más también en el de la autorratificación: basta su presencia para tome forma la particularidad de lo propio. El extranjero, su llegada, dirá Derrida, representa una oportunidad única de «apropiación de lo propio».

A través de la soberanía lo incondicional cristaliza en lo particular, de ahí que siempre se pueda interrogar la soberanía en nombre de lo incondicional del otro, del acontecimiento que la funda y al mismo la desvela. Existe un asedio de lo otro sobre el uno ${ }^{12}$, una heteronomía inerradicable como principio de destrucción de las certezas del sujeto autónomo. Hay identidad sólo si el Uno reprime lo (al) otro de sí: mas lo reprimido siempre retorna desde adentro. Esta es la paradoja de la soberanía: el poder performativo de sí, en el proceso de autocreación, incorpora al otro por su negación, creando simultáneamente un afuera en el adentro.

El lugar del tercero (no dialectizable) y los límites de la reflexión política clásica serían fundamentales para pensar el por venir de la emancipación y de la democracia. Aún cuando el espacio socio-político (la atribución y distribución de los lugares) se constituye en torno de lógicas binarias que buscan otorgar transparencia y visibilidad al mundo compartido, parte del trabajo de Derrida consiste en mostrar el travestismo de los conceptos y su carácter abierto. Si bien reconoce la productividad de la lógica oposicional, también muestra los puntos en los que los conceptos políticos no pueden ser simplemente contrapuestos y puestos al servicio de la identidad/diferencia. Dice Derrida en su seminario La bête et le souverain:

«La sola regla que por el momento creo que hay que darse en este seminario, es la de no fiarse de los límites oposicionales comúnmente aceptados entre naturaleza y cultura, naturaleza/ley, Phycis/nomos, Dios, hombre y animal o mismo alrededor de "lo propio del hombre", sin mezclar todo y sin precipitarse por analogismo, hacia "parecidos" o identidades. Cada vez que se pone en cuestión un límite oposicional, lejos de concluir una identidad, es preciso multiplicar por el contrario la atención sobre las diferencias, refinar el análisis dentro de un campo reestructurado» (Derrida, 2004, 444. Traducido por la autora).

Las figuras del soberano y la bestia tendrían en común el encontrarse "fuera de la ley», hecho que podría ser el principio de trascendencia hacia algo divino (lo suprahumano), pero también arrojo hacia la lascividad y la glotonería animal (lo infrahumano); remitiéndose a Aristóteles, 
aquel que vive por fuera de la comunidad (de su ley) sería una bestia o un dios, pero no un hombre:

«El estar fuera de la ley puede sin duda, por una parte, y esta es la figura de la soberanía, tomar la forma de el estar-por-arriba de las leyes, y por la tanto la forma de la Ley misma, del origen de las leyes, del garante de las leyes, como si la Ley, con una gran L, la condición de la ley, fuera antes, por encima y por lo tanto por fuera de la ley, exterior, heterogénea a la ley; pero el estar-fuera-de-la-ley puede también, por otra parte, y esta es la figura de aquello que se entiende más comúnmente por la animalidad o la bestialidad, situar el lugar en el que la ley no se manifiesta o no es respetada, o es violada» (Derrida, 2004, 445).

El estar fuera de la ley es la condición básica que permite la asociación y la complicidad de las figuras de la bestia, el criminal y el soberano: asedio mutuo de estas figuras sin ley. A través del rostro del soberano se manifiesta la geta de la bestia. No habría, como pretende la tradición política occidental, una frontera que permita separar el mundo animal y violento, del mundo humano de la ley. De ahí que Derrida sostenga la perversión inherente a los Estados. El Estado voyous o canalla, es aquel que no se aviene a ninguna ley, que actúa de espaldas a todo convenio, no reconociendo ninguna reglamentación común. En la estructura misma de la soberanía se encontraría inscrita la posibilidad de lo bestial, el estar-fuera-de-toda-ley (Derrida, 2004, 446).

\section{III}

Para Derrida, la exigencia de soberanía es indisociable de la exigencia incondicional de lo incondicionado. La crítica o hiper-crítica de la soberanía (la deconstrucción como emergencia de lo incalculable) surge de aquello mismo que la funda: el abismo de la singularidad. ¿En nombre de qué o de quién sería posible hacer una crí- tica de la soberanía, es decir, de la razón calculadora, de la razón de Estado? En nombre de la hospitalidad del otro cuya justicia infinita interroga cada vez lo existente en nombre de lo único no apropiable por nadie y nada: la singularidad. Se trata de pensar de otra manera el «yo puedo» a través de la figura del otro como acontecimiento, como aquello/aquel que no puede ser ni anticipado ni calculado: como apertura a la singularidad, como una estructura ineluctablemente hospitalaria del hombre, ética antes que ontológica.

Volviendo pues al motivo de este trabajo: se trata de la irrupción del y de lo otro, de aquel cuya dignidad no puede ser calculada, haciendo estallar en mil pedazos la unidad de un sujeto ya-siempre hospitalario ${ }^{13}$. La política sería la convergencia paradójica de lo condicional, cristalizado en la figura del derecho y de la soberanía que lo funda, y lo incondicional, como hospitalidad incondicional del radicalmente otro en su singularidad absoluta, que ningún cálculo soberano puede incorporar o prever. Un proceso crítico se desata sobre las certezas del soberano: éste, como la figura por excelencia de lo condicional, sólo puede ser lo que es reconociendo la incondicionalidad que lo funda y lo acecha: sólo hay soberanía ahí donde no existe prelación ${ }^{14}$.

$\mathrm{Si}$ se reconoce que no existe una identidad «natural», sino más bien una «construcción fantasmática de la identidad (del ethos) que busca naturalizar su origen» (Derrida, 1997a, 45) —es decir, que la incondicionalidad funda la soberanía del «yo» y el «nosotros»—, siempre que se hable de identidad, necesariamente, por justicia, se deberá tener en cuenta aquello que se excluye: es decir, la presencia/ausencia de todos aquellos cuya negación constituye una parte sustancial de la política por la cual se pueden hacer visibles los de adentro. He aquí la lógica sacrificial que Derrida reconoce $y$, sin 
embargo (instancia de la duda que abre el tiempo de una justicia sin tiempo), pone en cuestión a partir del concepto de hospitalidad como democracia.

Todo ordenamiento incluyente, dentro de una línea que se podría denominar «democrática», debería comprender muy bien lo que tanto Derrida como Espósito definen como la paradoja autoimunitaria, ya esbozada por Benjamin en su octava tesis sobre la historia: «Ningún sacrificio es demasiado grande para nuestra democracia, y menos que menos el sacrificio temporario de la propia democracia») (Agamben, 2004, 36). Derrida se encuentra en una línea de reflexión que se pregunta por el vínculo entre violencia y derecho que Benjamin ${ }^{15}$ ya habría hecho suyo. Reconoce que, aún cuando el orden sacrificial (la muerte actualizada, ritualizada y negada) constituye un secreto bien guardado al interior del orden común, las claves para su desnaturalización se encuentran en aquello mismo que lo funda y lo niega cada vez: la muerte (matando y disponiendo de la muerte del otro como si esto fuera posible), matando y muriendo para no morir ${ }^{16}$. Aquí el concepto de desapropiación de Derrida se encuentra en íntima relación con el concepto de Jean-Luc Nancy de desobra ${ }^{17}$; a través de ellos se deconstruye el lazo común a partir de aquello que no puede ser apropiado por nadie ni por nada: la singularidad. La muerte del otro pone al descubierto la finitud, sí, pero también la irremplazabilidad y el carácter incalculable de lo humano, la dignidad como fundamento de la pregunta por la justicia anterior a todo derecho y a todo cálculo.

Un gran escándalo es alojado en las entrañas de nuestras democracias: su máscara es la soberanía y la violencia que ellas excluyen e incorporan sin cesar. Dice Espósito en referencia a la hipótesis de Girard en La violencia y lo sagrado ${ }^{18}$ : «(...) si la comunidad logró salvarse de la deriva a la que su propia violencia continuamente la expone, es porque ya desde su inicio puso en funcionamiento un dispositivo inmunitario capaz de atenuar sus efectos devastadores. Esto equivale no a suprimir la violencia - en este caso, se extinguiría la comunidad, inseparable de ella - sino a asumirla en formas y dosis no letales» (Espósito, 2005, 58). El sistema inmunitario sería la condición trascendental, el modelo destructivo y operativo, de la comunidad (Ibíd., 205). Siguiendo los trazos de una tradición que somete los cuerpos, a vida y muerte, al cuerpo inmortal del Estado soberano, Espósito muestra cómo todo el paradigma político occidental se basa en la lógica inmunitaria ${ }^{19}$, en una matriz sacrificial centrada en la defensa contra las amenazas tanto internas como externas (cuya manifestación más clara es la doctrina de la soberanía). Mas no se trata (nunca, se podría decir) de los peligros que vienen de afuera sino de los que se gestan en el interior de estos ordenamientos, dando lugar al pasaje de la inmunidad a la auto-inmunidad: «las enfermedades autoinmunitarias son las que expresan, ya en su propia denominación, la contradicción más aguda: no una disminución, un bloqueo, una falla del aparato inmunitario, sino su vuelta contra sí mismo. (...) Algo está fuera de duda: en todos estos casos siempre se trata de un "exceso de defensa" del organismo que, en su intento de herir al enemigo, también se daña a sí mismo» (Ibíd., 230). Tanto Espósito como Derrida ponen en tela de juicio la identidad en nombre de la irrevocable hospitalidad del otro en el sí mismo: toda inmunidad es en realidad autoinmunidad, pues no hay un límite entre lo interior y lo exterior. Este punto representa uno de los puntos más relevantes para la presente indagación, pues el vínculo entre soberanía y hospitalidad, no dependería de un sujeto autónomo (in- 
dividuo/Estado) capaz de recibir, sino de un sí mismo en presencia/ausencia siempre-ya del otro irrumpiendo en su interior.

«Aunque aporía, double bind y proceso auto-inmunitario no sean meros sinónimos, sí tienen en común justamente, y más como una carga que como una contradicción interna, una indecidibilidad, es decir, una antinomia interna-externa no dialectizable que corre el riesgo de paralizar y requiere, por consiguiente, el acontecimiento de la decisión interruptora» (Derrida, 2005, 54).

$\mathrm{Si}$ bien es preciso reconocer que la identidad del sí mismo se gesta con la negación del otro, también no es menos cierto que el otro es constitutivo del sí mismo con anterioridad a toda negación y a toda dialéctica: la ipseidad sería la experiencia alérgica de una singularidad relacional, sin unidad ni a priori ni a posteriori. Como un juego de luces y sombras en el que necesariamente para dar luz (vida) al uno es preciso sacrificar al otro (que quedaría siempre allí-aquí, desde siempre, antes de toda conjura y apropiación, ilocalizable, al acecho). Lo otro constituye y acecha a la identidad desde adentro, de forma intermedia, espectralmente. De ahí que Derrida retome las paradojas autoinmunitarias que atraviesan todo ordenamiento democrático: un orden que para protegerse debe suspenderse, contradecirse, o "diluirse en sus fronteras": "Al operar en el espacio, la topología autoinmunitaria ordena siempre reenviar la democracia a otra parte, expulsarla o rechazarla, excluirla so pretexto de protegerla en el interior reenviando, rechazando, excluyendo fuera a los enemigos domésticos de la democracia» (Ibíd., 55). Toda democracia para protegerse debe suspenderse. Toda inclusión efectiva supone una exclusión. Pero, y este sería el principio democrático de la hiperpolítica defendido por Derrida, la democracia como apertura al y a lo otro por venir, sustraída como está a toda definición, podría ser redefinida a cada instante en función de lo que inevitablemente excluye, del y de lo otro como différance ${ }^{20}$.

Derrida renuncia al desarrollo de un programa. Desconfía de todo proyecto de comunidad, de todo ismo, pues cobija la sospecha de que la pervertibilidad es estructural a toda cristalización y manifestación del bien: siempre se corre el riesgo de hacer el mal creyendo hacer el bien (pharmakon $=$ remedio y veneno). Toda elección de un camino entraña la renuncia a muchos otros que se bifurcan en ese instante. Como el carácter de la vida es contingente y caótico, toda afirmación y estabilización soberana (del «yo» bajo al forma del individuo, la comunidad o el Estado) se encuentra siempre asediada y habitada constitutivamente por la perversión de su voluntad y el retorno siempre posible de lo reprimido: es decir, del otro negado. La afirmación soberana del «yo», en todas sus formas, incluso en las más democráticas, debe ser deconstruida, extendiendo su movimiento hacia lo anárquico y lo incondicional, hacia el caos del cual intenta salir a partir de estabilizaciones/proyectos auto-inmunitarios.

«(...) la deconstrucción, si algo semejante existiera, seguiría siendo, en mi opinión, ante todo un racionalismo incondicional que no renuncia nunca, precisamente en nombre de las Luces por venir, en el espacio por abrir de una democracia por venir, a suspender de una forma argumentada las condiciones, las hipótesis, las convenciones y las presuposiciones; a criticar incondicionalmente todas las condicionalidades, incluidas las que fundan todavía la idea de crítica» (Derrida, 2005, 170).

La «fe hipercrítica» ${ }^{21}$ de Derrida desconoce cualquier dogma, religión o frontera y resiste a asociarse a cualquier comunidad o institución. Para ir más lejos que la crítica, la deconstrucción habita y desencializa las lógicas binarias y dialécticas sobre la que normalmente descansan los proyectos políticos (aden- 
tro/afuera, amigo/enemigo, posible/imposible). No hay superación posible de la aporía y de la contradicción; campos heterogéneos tienden a cruzarse y a mantenerse en un reencuentro (im)posible. La soberanía (lo condicional, la ipseidad, la identidad) se ve constantemente cuestionada por lo incondicional (lo indiferente, el/lo otro siempre-ya presente en ella como fuente de su potencia y debilidad). El individuo, la comunidad, el Estado, como pro-yectos autoinmunitarios intentan neutralizar el acontecimiento.

«(...) todos los esfuerzos por atenuar o neutralizar el efecto del traumatismo (para negarlo, reprimirlo, olvidarlo, para hacer su duelo, etc.), son, a su vez, tentativas desesperadas. Y movimientos autoinmunes que producen, inventan y alimentan la monstruosidad que pretenden abatir. Lo que jamás se dejará olvidar es entonces el efecto perverso de la autoinmunidad misma. Hoy sabemos que la represión, en el sentido psicoanalítico y en el sentido político-policivo, político-militar, político-económico, produce, reproduce, regenera precisamente aquello que trata de desactivar» (Derrida, 2001, Edición digital).

La deconstrucción intenta habitar el entre en nombre del por-venir, de aquello que todavía no es, es decir, de la democracia como hospitalidad del otro. No se trata de una instancia crítica-superadora, sino de un trabajo sobre los conceptos que muestra sus limitaciones, su carácter no concluyente, sin un plan o un proyecto a priori para superarlos. La deconstrucción se propone redefinir el sentido de lo que nos parece natural o indiscutible, no para «depurar mentiras»y «hacer visible una verdad», sino para asumir la contrariedad de los conceptos y las instituciones; es decir, su carácter político, discutible y abierto. Así, en el caso particular del Estado como instancia de integración, no sólo trata de dirigir la crítica hacia las doctrinas y los conceptos que lo fundan (poniendo especial atención en la soberanía), sino también hacia el conjunto de instancias que se proponen reemplazarlo. No se trata de privilegiar una única instancia de integración sino más bien de multiplicar y revitalizar hiper-críticamente nuevas y viejas formas de integración: no se trata de suprimir el Estado o las distintas instancias internacionales, sino de mostrar, en cada caso, los limites de sus prácticas y conceptos para empujarlos un poco más allá de ellos mismos, justamente, en nombre de la hospitalidad.

\section{BIBLIOGRAFÍA}

Abensour, Miguel (1998): La democracia contra el Estado, Buenos Aires, Editorial Colihue.

Agamben, Giorgio (1998): Homo Sacer. El poder soberano y la nuda vida, Valencia, Editorial Pre-textos.

- (2004): Estado de Excepción, Buenos Aires, Editorial Adriana Hidalgo.

Benjamin, Walter (1995): Para una crítica de la violencia, Buenos Aires, Editorial Leviatán.

Blanchot, Maurice (1999): La comunidad inconfesable, Madrid, Editorial Arena.

Crick, Bernard (1977): «Soberanía» en Sills, D. (ed.), Enciclopedia internacional de las ciencias sociales, Aguilar, Madrid.

Derrida, Jacques (1997): Cosmopolites de tous les pays, encore un effort!, Paris, Editorial Galilée.

- (1997a): Fuerza de ley. El «fundamento místico de la autoridad», Madrid, Editorial Tecnos.

- (1998): Adiós a Emmanuel Lévinas. Palabra de acogida, Madrid, Editorial Trotta.

- (2001): «Autoinmunidad: suicidios reales y simbólicos» Edición digital (http://www.jacquesderrida.com.ar/ textos/septiembre.htm). Entrevista de Giovanna Borradori con Jacques De- 
rrida el 22 de octubre de 2001 en New York.[i] Traducido del francés por: J Botero en La filosofía en una época de terror. Diálogos con Jürgen $\mathrm{Ha}$ bermas y Jacques Derrida, Buenos Aires, Editorial Taurus.

- (2004): «La bête et le souverain» en La Démocratie a venir. Autour de Jacques Derrida, Marie-Louise Mallet (dir.), Paris, Editorial Galilée.

- (2005): Canallas. Dos ensayos sobre la razón, Madrid, Editorial Trotta.

Espósito, Roberto (2005): Inmunitas. Protección y negación de la vida, Buenos Aires, Editorial Amorrortu. Girard, René (2002): La violencia y lo sagrado, Barcelona, Editorial Anagrama.

Goffman, Erving (1967): El ritual de interacción, Madrid, Editorial Tiempo Contemporáneo.
Kant, Emmanuel (1989): Metafísica de las Costumbres, Madrid, Editorial Tecnos.

- (2004): Ideas para una historia universal en clave cosmopolita/ Hacia la paz perpetua, Buenos Aires, Editorial Ladosur.

Mairet, Gérard (1997): Le principe de souveraineté. Histoires et fondements du pouvoir moderne, Paris, Ed. Gallimard.

Nancy Jean-Luc (2001): La comunidad desobrada, Madrid, Editorial Arena.

Schérer, René (1997): «Cosmopolitisme et hospitalité» en Hospitalité Communications $N^{\circ} 65$, EHESS-CET, Paris, Editions Seuil.

Schmitt, Carl (1963): El concepto de lo político, Buenos Aires, Editorial Folios.
1 «Por "ipseidad" sobreentiendo, por lo tanto, algún "yo puedo" o, como poco, el poder que se otorga a sí mismo su ley, su fuerza de ley, su representación de sí mismo, la reunión soberana y reapropiadota de sî en la simultaneidad del ensamblaje o de la asamblea, del estar-juntos, del "vivir juntos", como se dice también. (...) Entenderé pues tanto el sí mismo, el "mismo de sí" (es, decir el mismo, meisme, que viene de metiese), como el poder, la potencia, la soberanía, lo posible implicado en todo "yo puedo", pse del ipse (ipsissimus) que remite siempre - Benveniste lo muestra perfectamente-, a través de complicados relevos, a la posesión, a la propiedad, al poder, a la autoridad del señor, del soberano y, casi siempre, del anfitrión (hospites), del señor de la casa o del marido» (Derrida, 2005, 28).

2 En esta línea es preciso seguir los pasos de Lévinas y los de Derrida a través de aquél: «El en-casa de la morada no significa el cierre sino el lugar del Deseo dirigido a la trascendencia del Otro. La separación señalada en él es la condición de la acogida y de la hospitalidad ofrecida al otro. No habría ni acogida ni hospitalidad sin esa alteridad radical que supone ya separación. El vínculo social es una cierta experiencia de la desvinculación sin la cual ninguna respiración, ninguna inspiración espiritual sería posible. El recogi- miento, el estar-juntos mismo supone la separación infinita. El en-casa no será ya, por consiguiente, naturaleza o raíz, sino respuesta a una enrancia, fenómeno de la errancia que él detiene» (Derrida, 1998, 120).

3 Carl Schmitt, con intenciones diametralmente opuestas a las que guían la presente investigación, lo explica muy bien. Según este autor, el campo político es el escenario de un enfrentamiento entre distintas formas de vida colectiva que no pueden resolver sus diferencias racionalmente. Los conflictos surgen de una diversidad existencial inerradicable que no puede resolverse por medio de la moral o de las leyes. De ahí que la decisión política fundamental sea aquella que determina para el conjunto quién es el enemigo: «El enemigo es simplemente el otro, el extranjero y basta a su esencia que sea existencialmente, en un sentido particularmente intensivo, algo otro o extranjero, de modo que, en el caso extremo sean posibles con él conflictos que no puedan ser decididos ni a través de un sistema de normas preestablecidas ni mediante la intervención de un tercero "descomprometido" y por eso "imparcial"» (Schmitt, 1963: 23). El Estado, en sentido político, debe ser aprehendido en el horizonte de la guerra. De ahí las críticas a la idea liberal de individuo universal, racional y moral y a la posibilidad de resolución racional de los conflictos. Para Schmitt, 
la teoría de la Constitución del Estado de Derecho, fundada en la doctrina de los derechos naturales y universales del hombre como garantías contra el Estado, es claramente antipolítica, pues busca aplazar y negar el problema de la soberanía, es decir, la determinación de un enemigo que haga posible la afirmación de la existencia colectiva.

4 La democracia contra el Estado (1998) de Miguel Abensour es un buen ejemplo. Dentro de esta línea también está Derrida que critica al Estado, una política condicional basada en lo jurídico, partiendo de la Justicia, de una política incondicional y de una democracia por venir.

5 «El soberano está, al mismo tiempo, fuera y dentro del ordenamiento jurídico. Si es soberano es, en efecto, aquél a quien el orden jurídico reconoce el poder de proclamar el estado de excepción y de suspender, de este modo, la validez del orden jurídico mismo, entonces cae, pues, fuera del orden jurídico normalmente vigente sin dejar por ello de pertenecer a él, puesto que tiene competencia para decidir si la Constitución puede ser suspendida "in toto". La precisión "al mismo tiempo" no es trivial: el soberano, al tener el poder legal de suspender la validez de la ley, se sitúa legalmente fuera de ella. Y esto significa que la paradoja de la soberanía puede formularse también de esta forma: "La ley está fuera de sí misma", o bien: "Yo, el soberano, que estoy fuera de la ley, declaro que no hay un afuera de la ley"» (Agamben, 1998, 27).

6 «El concepto de soberanía debe reservarse para la afirmación condicional de que todos los gobiernos deben hacer frente a condiciones excepcionales en las que las normas constitucionales ordinarias deben ser marginadas, si es que el Estado pretende sobrevivir (...). La soberanía es relevante en relación con las situaciones de excepción o de emergencia como potencialidad para mantener el orden en presencia de peligros ciertos y reales y como justificación de poderes de excepción en los que todos los regímenes deben encontrar la capacidad para una acción decisiva, centralizada e incuestionada, al menos durante cierto tiempo, si el Estado debe sobrevivir» (Crick, 1979, 771-772).

7 «(...) el principio de soberanía (...), tratándose del hecho fundamental de la modernidad, se ha mostrado como el principio de individuación de los pueblos históricos. Pueblos y naciones han construido su identidad propia a través del Estado. Una construcción tal, vivida por los modernos como el medio para alcanzar la libertad misma, se ha operado a través y por la guerra, civil o externa, en todo caso por la violencia. La construcción de la territorialidad política de los Estados, como materialización del principio de soberanía, constituye el telón de fondo de la historia moderna» (Mairet, 1997, 13. Traducido del francés por la autora).

8 «Existe siempre una distancia considerable entre la generosidad de los grandes principios del derecho de asilo heredados de las Luces o de la Revolución
Francesa y, por otro lado, la realidad histórica o la concreción efectiva de estos principios» (Derrida, 1997, 30).

9 En Adiós a Emmanuel Lévinas Derrida opera su ruptura con el cosmopolitismo kantiano a partir del concepto levinasiano de hospitalidad: «Mientras que para Kant la institución de la paz no podía más que conservar la huella de un estado de naturaleza guerrera, en Lévinas, inversamente, la alergia, el rechazo del otro, la guerra aparece en un espacio marcado por la epifanía del rostro, precisamente donde "el sujeto es un anfitrión" y un "rehén", allí donde, responsable, traumatizada, obsesionada, perseguida, la subjetividad intencional, la conciencia-de, ofrece de antemano la hospitalidad que ella es. Cuando afirma que "la esencia del lenguaje es amistad y hospitalidad", Lévinas entiende que está marcando una interrupción: interrupción de la simetría e interrupción de la dialéctica. Rompe con Kant y con Hegel: y con un jurídico-cosmopolitismo que, a pesar de sus denegaciones, no llegaría a interrumpir la paz armada, la paz como armisticio; y asimismo con el laborioso proceso de lo negativo, con un "proceso de paz" que organizaría a su vez la guerra por otros medios cuando no hace de ella una condición de la conciencia, de la "moralidad objetiva" y de la política - eso mismo acerca de lo cual una dialéctica de un Carl Schmitt daba crédito nuevamente a Hegel. Para Lévinas, la paz no es un proceso de lo negativo, el resultado de un tratado dialéctico entre lo Mismo y lo Otro: "Lo Otro no es la negación de lo Mismo como lo querría Hegel. El hecho fundamental de la escisión ontológica en Mismo y en Otro es una relación no-alérgica de lo Mismo con lo Otro"» (Derrida, 1998, 119).

10 «En lo que se refiere a las relaciones exteriores de los Estados, no se puede exigir a un Estado que abandone su constitución, aunque sea despótica - que es la más fuerte con relación a los enemigos exteriores-, mientras corra el peligro de ser conquistado rápidamente por otros Estados. Así, pues, queda permitido, en algunos casos, el aplazamiento de las reformas hasta mejor ocasión» (Kant, 2004, 62-63). Este tipo de reflexiones son las que justamente permiten entender, según Derrida, cómo se produce y cuáles son las razones profundas de la autoinmunidad que se aborda más adelante en este mismo texto.

11 «AAcaso no se puede y no debe distinguir, precisamente allí donde eso parece imposible, entre, por un lado, la compulsión o la auto-posición de soberanía (que es asimismo, nada menos, la de la ipseidad misma, del mimo sí mismo [meisme, de metipsissimus, meisme], ipseidad que conlleva, como lo confirmaría también la etimología, la posición de poder androcentrada del amo de la casa, el dominio soberano del señor, del padre o del marido, la potencia de lo mismo, del ipse como sí mismo) y, por otro lado, esa postulaciónde incondicionalidad que se encuentra tanto en la exigencia crítica como en la exigencia (perdónenme la palabra) reconstructiva de la razón?» 
«(...) No se trataría sólo de disociar pulsión de soberanía y exigencia de incondicionalidad como dos términos simétricamente asociados, sino de cuestionar, de criticar, de deconstruir, si quieren, la una en nombre de la otra, la soberanía en nombre de la otra» (Derrida, 2005, 171).

12 «Más que formar parte de ella, el individuo mismo es una comunidad infinitamente plural» (Espósito, 2005, 190).

13 Derrida retoma a Nancy ahí donde éste hace posible pensar una libertad como heteronomía, más allá de la fuerza y el poder: «Nancy pretende efectivamente abrir de nuevo el acceso a una libertad que "no se deja presentar como autonomía de una subjetividad dueña de sí misma y de sus decisiones, desarrollándose $\sin$ trabas, con una perfecta independencia"» (Derrida, 2005, 61).

14 El Bien, nos dice Derrida, es la primera figura de lo incondicional que funda la soberanía. En la $R e-$ pública «lo invisible es fuente de lo visible, de la visibilidad invisible de lo visible, de una condición de visibilidad que es ella misma invisible e incondicional» (Derrida, 2005, 165). Platón se pregunta ¿cómo debe ser la ciudad perfecta en la que reina absolutamente la Idea de Justicia? En una primera respuesta nos arroja al terreno de la utopía, al horizonte puro y racional desde el cual reconstruir la pólis en crisis. El carácter "extraterritorial" de la República pareciera dejar abierto el campo de lo posible más allá de lo actual. Si bien el proyecto de comunidad racional se funda en la dimensión necesaria e inmutable de la Idea de Justicia, ésta no se deja aprehender tan fácilmente; su justificación política implica una transacción (siempre imposible) entre lo contingente y lo sensible (lo incalculable) y lo necesario (a primera vista lo calculable y lo finito). Estamos frente al tránsito imposible de la justicia - incondicional y absoluta - al derecho - condicional y relativo a la comunidad-. La Justicia es deconstrucción (irrupción y hospitalidad del radicalmente otro): desborda siempre la capacidad reflexiva y lógica de la razón, ya sea bajo la forma del lógos, del mito o de la ley. La Justicia nos reenvía al marco pre-mito-lógico de la filosofía platónica (pre-mito-lógico porque si bien lo mítico abre el camino hacia lo verosímil - el mito de las razas - kôra en tanto exceso no dialectizable nos empuja hacia el "abismo sin fondo"). Si bien la filosofía platónica busca hacer "comunicable" y de naturaleza práctica lo justo a través de las narraciones míticas, lo cierto es que la materialización de (incluso) la mejor de las comunidades conlleva la perfección/perversión del proyecto. De ahí que justicia/kôra/deconstrucción sea siempre una estructura universal indeconstruible e hiper-crítica, lo invisible, un secreto irreductible e incomunicable (el secreto de la última morada del hombre y la mujer); aquello que dejaría siempre lugar a una redefinición del derecho/de lo dicho/del texto y (nuevamente) a una repolitización (reasignación de las partes) de la comunidad.
15 Para el vínculo de derecho y violencia remitirse a Para una crítica de la violencia (1995) de Walter Benjamín.

16 «El hecho es que Bataille no siempre advirtió - aunque fue el que más lo advirtió - que la comunidad no puede hacerse obra: ni de vida, ni de muerte, ni de cada cual, ni de todos. Es cierto que Bataille no buscó en el sacrificio la inmortalidad de la existencia, sino, por el contrario, la prueba cruenta de su finitud. No obstante, justamente aquí, en la iluminación de esta verdad extrema, está la zona de sombra que empañó su lucidísima perspectiva, cuando se prohibió ver en la existencia lo que no se puede sacrificar» (Espósito, 2003, 207).

17 «[La comunidad] Está consignada a la muerte como a aquello de lo que es, precisamente, imposible hacer obra (excepto obra de muerte, desde que se quiere obrar como ella...)» (Nancy, 2001, 34).

18 En el libro La violencia y lo sagrado, Girard nos coloca frente a una posible respuesta a la pregunta acerca las razones profundas de los procesos por los cuales determinados miembros aparecen como «extraños»y, de forma más radical, como sagrados y sacrificables. Según este autor, para existir toda cultura y sociedad debe resolver el tema de la violencia; los hombres tienen naturalmente un apetito de violencia que, cuando no está regulado socialmente y diferido, se desparrama por doquier haciendo imposible la sociedad. El sacrificio cumple una función central, puesto que a través de él se restaura la armonía y se refuerza la unidad social. Ahora bien, el punto más interesante remarcado por Girard en el horizonte de la presente indagación, es el que se refiere a los rasgos comunes al conjunto de las víctimas sacrificiales; éstas se caracterizan principalmente por no pertenecer o pertenecer de forma incompleta al grupo social, esto es, por no integrarse plenamente (los extranjeros, los niños, las vírgenes, los animales, los reyes, etc.). La hipótesis de Girard es que entre la comunidad y las víctimas no existe una relación social particularizada.

Según Girard la justicia se basa principalmente en el orden diferencial. Cuando un grupo social pierde la capacidad de colocar por fuera a ciertas personas en base a ciertos elementos de diferenciación, se pone en jaque el orden sacrificial ya que al no polarizarse la violencia sobre los «otros», los «enemigos» y los «diferentes» la violencia intestina consume al grupo social en un sinfín de acciones y respuestas. De esta forma, insiste en que «las razones que impulsan a los hombres a exterminar algunas de sus criaturas pueden ser sin duda malvadas pero es difícil que sean triviales» (Girard, 2002, 32) y nos invita a pensar en el conjunto de mecanismos por los cuales se ponen en marcha los procesos de exclusión y extrañeza en todos los grupos sociales. Para un análisis detallado de la tesis de Girard se recomienda la lectura del capítulo «Sangre doble» de Inmunitas: "Desde esta perspectiva, se debería decir que la comunidad es una violencia diferida, que se diferencia de sí mis- 
ma duplicándose en otra violencia. La hendidura que por un momento se abre en el corazón de la violencia, para volver a cerrarse inmediatamente después como tenaza en torno de la víctima designada. Un cambio de lugar de la violencia, de lo propio a lo otro. De todos a uno: todos menos uno. Uno en lugar de todos. Aún cuando asume la forma de la no-violencia, cuando parece anhelar la paz, la comunidad es el fruto oculto - una concesión y un producto- de la violencia» (Espósito, 2005, 59).

$19 \ll(\ldots)$ el sistema inmunitario es un mapa dibujado para guiar el reconocimiento y el desconocimiento del sí mismo y del otro en la dialéctica de la política occidental» (Ibíd., 205).

20 «Si lo prefieren ustedes, esta democracia como envío del reenvío, reenvía a la différance. Pero no sólo a la différance como prórroga y rodeo del rodeo, vía desviada, aplazamiento de la economía de lo mismo.
Pues se trata también, y a la vez — ya que la cosa está marcada por la misma palabra en différance-, de la différance como reenvío a lo otro, es decir, como experiencia irrefutable - subrayo: irrefutable - de la alteridad del otro, de lo heterogéneo, de lo singular, de lo no-mismo, de lo diferente, de la disimetría, de la heteronomía» (Derrida, 2005, 57).

21 «Esta fe es otra forma de guardar razón, por loca que parezca. Si el mínimo semántico que se pueda conservar de los léxicos de la razón, en todas las lenguas, es la última posibilidad sino de un consenso, al menos de una interpelación universalmente prometida e incondicionalmente confiada al otro, entonces la razón sigue siendo el elemento o el soplo de una fe sin iglesia ni credulidad, la razón de ser del compromiso, del crédito (testimonio) más allá de la prueba, la razón de ser del creer al otro o en el otro $-\mathrm{y}$, por consiguiente, también del perjurio» (Derrida, 2005, 183). 